\title{
AVALIAÇÃO DO CRESCIMENTO DE RADÍCULAS DE MILHO EXPOSTAS A DIFERENTES CONCENTRAÇÕES DO HERBICIDA 2,4-D
}

\author{
Isabela Breder Vargas ${ }^{1}$ \\ Rogério de Souza Nóia Júnior ${ }^{2}$ \\ José Augusto de Oliveira David ${ }^{3}$
}

\begin{abstract}
Resumo: A utilização de agrotóxicos se faz presente em todo o Brasil, alguns possuem efeitos mutagênicos em células vegetais já provados, e seu uso indiscriminado pode levar a contaminação do solo e da água. Dentre esses produtos químicos, destaca-se os herbicidas que são muito utilizados na agricultura, no qual encontra-se inserido o ácido diclorofenoxiacético ou 2,4-D. O uso deste herbicida é recomendado em culturas de milho, entretanto, ainda são escassos trabalhos na literatura que demonstram seu efeito nas células deste vegetal, o que levou este trabalho a avaliar os efeitos do herbicida 2,4-D, em diferentes concentrações, no ciclo celular de células da raiz de milho (Zea mays). Os resultados demonstraram que há redução no crescimento de raízes de milho conforme é aumentada a concentração do herbicida, demonstrando a sensibilidade de tal semente ao herbicida, que acaba por induzir sua taxa de crescimento. Palavras-chave: Crescimento; Ecotoxicologia; Herbicida; Mutagenicidade; 2,4-D.
\end{abstract}

\footnotetext{
1 Universidade Federal do Espírito Santo, Brasil. E-mail: isabelabvargas@gmail.com.

2 Universidade Federal do Espírito Santo, Brasil. E-mail: rogeriosouzanoia@gmail.com.

3 Universidade Federal de São Carlos, Brasil. E-mail: joseaugustodavid@hotmail.com.
} 